\title{
Extrinsic and intrinsic motivation in online education during the pandemic as perceived by Lithuanian and Romanian university students
}

\author{
Vincentas Lamanauskas, Rita Makarskaitė- \\ Petkevičienè \\ Vilnius University, Lithuania \\ Vincentas.lamanauskas@sa.vu.lt, rita.makarskaite- \\ petkevicienelfsf.vu.lt \\ Valentina Iuliana Manea \\ Technical University of Building Engineering, \\ Bucharest, Romania \\ valentina.maneadutcb.ro
}

\author{
Gabriel Gorghiu \\ Valahia University of Targoviste, \\ Romania \\ ggorghiuegmail.com \\ Costin Pribeanu \\ Academy of Romanian Scientists, \\ Bucharest, Romania \\ costin.pribeanu@gmail.com
}

\begin{abstract}
The pandemic generated by the Coronavirus COVID-19 challenged universities to go exclusively online thus affecting both the education and personal life of teachers and students. This work analyzes the perceptions of Lithuanian and Romanian university students as regards the extrinsic and intrinsic motivation of online learning during the pandemic. Following the technology acceptance theory, extrinsic motivation has been operationalized as the perceived usefulness and intrinsic motivation as the perceived enjoyment. Although the results show a low to moderate motivation for online/distance learning, interesting differences between the two motivating factors have been found, as well as between the perceptions of students from the two countries.
\end{abstract}

\section{Keywords}

Online education, online lectures, online educational platform, intrinsic motivation, extrinsic motivation, TAM, pandemic.

\section{ACM Classification}

D.2.2: Design tools and techniques. H5.2 User interfaces.

DOI: $10.37789 /$ rochi.2021.1.1.23

\section{INTRODUCTION}

The pandemic generated by the Coronavirus COVID-19 challenged universities to reset their traditional education activities. Both teaching and learning went online because of the mobility restrictions. Although online learning is not new, exclusive online education is something different and proved to affect both the education and personal life of teachers and students $[11,29]$.

It is agreed that several factors which are determinants for online learning have an important potential to diminish the students' motivation to learn [5]. First, the absence of the teacher-student relationship in a face-to-face format makes online communication unable to provide for teachers the same opportunities to interpret and observe the students' reactions during the classes, in order to easily assess their level of attention and motivation. In addition, a close teacherstudent relationship can be essential in motivating students to learn, but - as recorded in many circumstances - online communication can often be impersonal, superficial, and disrupted. However, the online learning environment can provide a relative level of anonymity - students can virtually participate in online activities, but their attention is possible to be focused on other issues. Finally, the difficulties related to comprehension may be higher during online lessons. The more difficult the lesson topic is, the less motivated the student will be to learn because the student will feel discouraged.

All the radical changes recorded in world educational systems happened in a short period and have put teachers and students in the situation to rely solely on the online platform available in their university. Unfortunately, few studies exist at the moment, that evaluate the usability of the technology in a given context of use, although this is an important issue in an exclusive online environment [31]. Also, few studies exist that assess the technology acceptance before its use at a large scale.

As Hornbaek \& Hertzum pointed out [17] the adoption and use of information technology is a central concern in humancomputer interaction HCI. The acceptance of the technology is driven by various factors, among which the most important is the perceived ease of use and the user's motivation to adopt and use a given technology [8]. In the context of the technology acceptance model (TAM), extrinsic motivation has been conceptualized as perceived usefulness and intrinsic motivation has been conceptualized as perceived enjoyment [8].

Motivation is an important driver of technology acceptance 


\section{Proceedings of RoCHI 2021}

by influencing both the actual use and the intention to continue using the system in the future [8]. A motivational model explains technology acceptance with two key factors: extrinsic motivation and intrinsic motivation. While the former is instrumental, being goal-oriented, the latter is hedonic, being related to pleasure and inherent satisfaction created by a specific activity $[14,16]$.

At the same time, in many institutions, organized information systems, easy access to documents, a high level of workflow automation, elimination of routine tasks, or good collaboration, are factors that contribute to the increasing of the employees' motivation. In this respect, such patterns can be easily transferred to educational systems, not just when embracing the online learning format, but even in face-to-face ones, taking also into strict account that "self-motivation and well-being are enhanced when innate needs for autonomy, competence, and relatedness would be satisfied, but also diminished when those needs are thwarted" [3].

However, motivation remains one of the main issues in online learning which should maintain the students' feelings of behavior, emotional and cognitive engagement, and success $[1,6,15,21,24]$. Several authors found that online studies conducted in the context of the COVID-19 pandemic had a strong impact on students' learning motivation [18, 23, 33].

The main aim of the present work was to analyze the perceptions of Lithuanian and Romanian students as regards the extrinsic and intrinsic motivation of online lectures using an online platform during the pandemic. The analysis was done on two samples of 158 Lithuanian students, respectively 354 Romanian students then an invariance analysis using multigroup confirmatory analysis is done as a precondition for group comparison.

The rest of the paper is organized as follows. In section 2, related work is discussed with a focus on the technology acceptance and motivation factors. The method and sample are presented in section 3. Then, the model testing and invariance analysis results are presented and discussed in section 4 . The paper ends with a conclusion in section 5 .

\section{RELATED WORK}

\section{Technology acceptance}

The self-determination theory [9] analyzed two forms of motivation: extrinsic and intrinsic focusing on the intrinsically motivated behaviors that are are the prototypes of self-determination. Recently, Deci and Ryan [10] showed that intrinsic and well-internalized forms of extrinsic motivation have o positive influence on positive educational outcomes. A self-determined student is an intrinsically motivated individual who goes through a process of internalization and has control over their own behavior [10].

In the context of technology acceptance, the extrinsic motivation was conceptualized as perceived usefulness, defined by Davis, Bagozzi, and Warsaw [8] as "the degree to which a person believes that using a particular system would enhance his or her job performance". The intrinsic motivation was conceptualized as perceived enjoyment, defined as "the extent to which the activity of using a specific system is perceived to be enjoyable in its rights, aside from any performance consequences resulting from system use" [8].

\section{Motivation in online learning}

Malinauskas and Požeriene [21] explored the motivation of university students studying in classrooms/lecture halls (conventional mode) and studying online. The motivation scale (SAMS-21) was used to examine internal and external motivation. The study showed that students studying online had higher internal motivation scores than students who attended lectures directly. The results did not show a significant difference between the gender.

One recent research [18] suggests that distance learning is ambiguous: on the one hand, it helps to support the study (learning) process despite the physical and social isolation associated with the pandemic, on the other hand, it can have unintended negative consequences for lecturers, reduce their satisfaction and involvement. In addition, online studies can be perceived as a subject of lower motivational potential compared to the conventional study mode.

Another study (proposed by Amrai et al. [1]) showed that motivational factors play a crucial role in students 'academic achievement. As academic achievement is related to the development of society, education policymakers are suggested to pay more attention to the motivation component.

Sharma et al. [36] explored deep motivation by gaze analysis, which is defined as creating intrinsic motivation to learn. The study used With-me-ness, which measures what students pay attention to when a lecturer says or shows. This defines the levels of interaction of the participants in the educational process: perception and conceptuality. It has been found that the lecturer-student perspective when learning online is a very important source of information (both attention and information processing).

A study by Maqbool et al [24] showed that distance learning has a strong association with study/learning satisfaction. Learning motivation is closely related to the lecturer and the curriculum (study program). The quality and presentation and evaluation of students' work is also related to motivation, but it is not as strong as the factor of satisfaction with studies.

Rahiem [33] argues that students, despite the pandemic, have a positive attitude to learning. They coped with the challenges thanks to their enthusiasm and understanding of the need to stay at home for the benefit of all. The home environment helped them focus on learning, so they made progress in their studies. They see challenges that students were unprepared for and negative experiences as an opportunity for improvement.

Another study conducted in the United States found that students attending distance learning courses demonstrated significantly lower motivation to study than students attending regular lectures [32]. 
Completing the list of studies, a recent one performed in Mozambique showed that students perceive various demotivating factors: insufficient feedback from their lecturers, a high workload at home, technical difficulties, which determines demotivation and dropout [25].

Finally, the study made by Daniels et al [6] emphasizes the importance of goals in maintaining students' feelings of behavior, emotional and cognitive engagement, and success. Students were found to be most involved during the pandemic and had a higher perception of success. However, their achievements are associated with a certain level of dishonesty.

\section{METHOD AND SAMPLE}

This research is focusing on two latent variables: the intrinsic motivation - operationalized as perceived enjoyment (PE), and the extrinsic motivation - operationalized as perceived usefulness (PU). The variables analyzed in this work are presented in Table 1.

Table 1. Variables

\begin{tabular}{|l|l|}
\hline PE1 & Online lectures make learning more attractive \\
\hline PE2 & Online lectures make learning more enjoyable \\
\hline PE3 & Online lectures make learning more interesting \\
\hline PU1 & $\begin{array}{l}\text { The online platform could enhance my school } \\
\text { performance }\end{array}$ \\
\hline PU2 & $\begin{array}{l}\text { Using the online platform would improve my school } \\
\text { work }\end{array}$ \\
\hline PU3 & $\begin{array}{l}\text { The use of the online platform would give me an } \\
\text { advantage }\end{array}$ \\
\hline
\end{tabular}

The unidimensionality has been assessed by examining the loadings $(\lambda)$ and t-values. The scale reliability has been assessed with Cronbach's alpha. The convergent validity has been analyzed by examining the composite reliability (CR) and average variance extracted (AVE), following the recommendations of FL [12].

The model specification is presented in Figure 1.

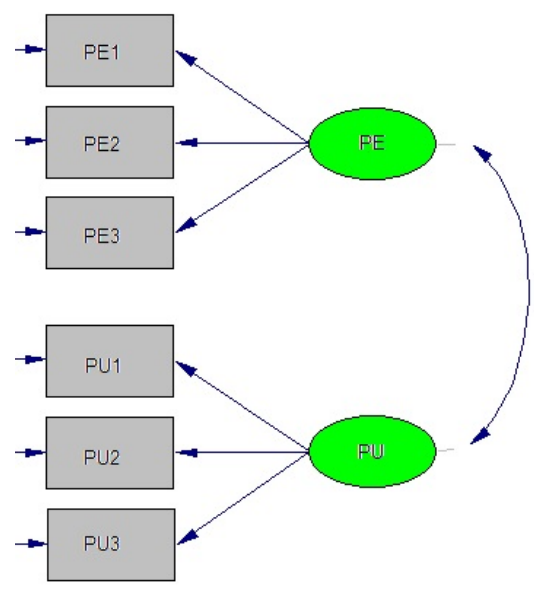

Figure 1. The measurement model

Based on the recommendations from the literature [H06, SMM03], the fit between the model and the data has been assessed with the following goodness-of-fit (GOF) indices: chi-square $\left(\chi^{2}\right)$, normed chi-square $\left(\chi^{2} / \mathrm{DF}\right)$, comparative fit index (CFI), goodness-of-fit index (GFI), standardized root mean square residual (SRMR), and root mean square error of approximation (RMSEA).

To analyze the differences between the two groups, an invariance analysis is required that checks if the constructs are equivalent across groups [2, 28, 38]. A multi-group CFA (MGCFA) using Lisrel for Windows [26] has been conducted to check if the scale is invariant across countries. MGCFA is based on testing a hierarchical series of nested models, starting with a baseline model that fits all the samples together.

A questionnaire has been administrated to Lithuanian and Romanian students in 2021. Students were asked to answer some general questions, then to rate several statements on a 5-point Likert scale

The Lithuanian sample $(\mathrm{N}=158)$ consists of 6 men and 152 women. Most students are undergraduates in the area of primary and childhood education. The Romanian sample $(\mathrm{N}=354)$ consists of 159 men and 195 women. Students are from two universities: Technical University of Building Engineering $(\mathrm{N}=214)$ and Valahia University $(\mathrm{N}=140)$, most of them being enrolled in technical studies, and at the same time, in the programs proposed by the Teacher Training Departments from both institutions - educational structures authorized to offer psycho-pedagogical training programs, with the view to exercise (after graduation) the teaching profession.

\section{MODEL ESTIMATION RESULTS}

\section{Lithuanian sample}

The first step is to test the model for each sample. The model estimation results for the Lithuanian sample are presented in Figure 2. 


\section{Proceedings of RoCHI 2021}

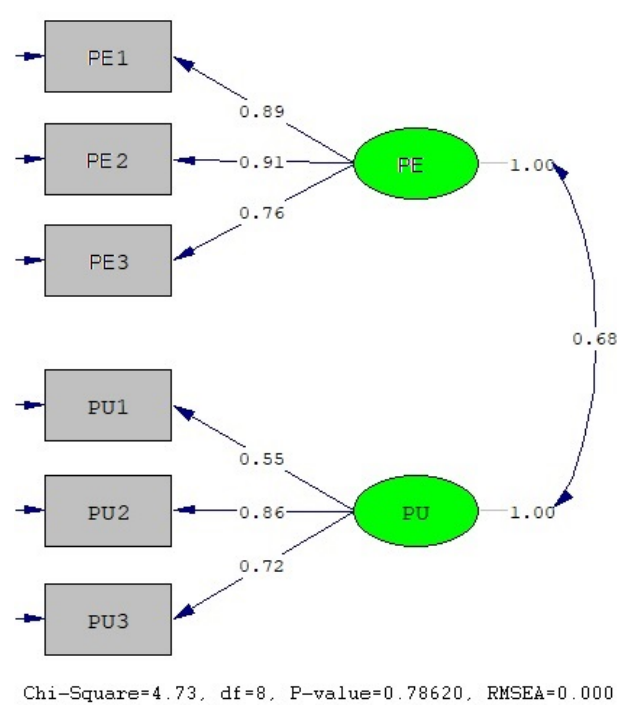

Figure 2. Model estimation results $(N=158)$

The descriptive statistics (mean and standard deviation), factor loadings $(\lambda)$, and item reliability $\left(\mathrm{R}^{2}\right)$ for the Lithuanian sample are presented in Table 2. Students scored higher the perceived attractiveness,

Table 2. Descriptive statistics and factor loadings $(N=158)$

\begin{tabular}{|l|l|l|l|l|}
\hline Item & $\mathrm{M}$ & $\mathrm{SD}$ & $\lambda$ & $\mathrm{R}^{2}$ \\
\hline PE1 & 3.20 & 1.26 & 0.89 & 0.79 \\
\hline PE2 & 2.98 & 1.25 & 0.91 & 0.84 \\
\hline PE3 & 2.75 & 1.21 & 0.76 & 0.59 \\
\hline PU1 & 3.23 & 0.93 & 0.55 & 0.30 \\
\hline PU2 & 2.99 & 1.14 & 0.66 & 0.74 \\
\hline PU3 & 3.25 & 1.11 & 0.72 & 0.52 \\
\hline
\end{tabular}

The correlation coefficient of 0.68 between the latent variables is statistically significant $(\mathrm{p}<.001)$.

With one exception, all factor loadings are over 0.6 and item reliability over 0.5 , thus proving unidimensionality. The scale reliability (Cronbach's alpha) was over 0.7 for both constructs. The composite reliability (CR) of the two constructs was above the threshold of 0.7 and the average variance extracted (AVE) was above the threshold of 0.5 , thus showing convergent validity.

The model fit with the data is very good. The goodness-of-fit (GOF) indices are within the limits recommended by Hair et al. [H06]. The GOF indices are presented in Table 3.

Table 3. GOF indices $(N=158)$

\begin{tabular}{|l|l|l|l|l|l|l|}
\hline$\chi^{2}$ & DF & $\chi^{2} / \mathrm{DF}$ & RMSEA & CFI & GFI & SRMR \\
\hline 4.73 & 8 & 0.59 & 0.000 & 1.00 & 0.99 & 0.020 \\
\hline
\end{tabular}

The mean values of the indicators show that Lithuanian students perceived the online lectures as being attractive and considered that using the online platform may lead to better school performance and may give them an advantage. Three items (PE2, PE3, and PU2) were scored below the neutral value.

\section{Romanian sample}

The model estimation results for the Romanian sample are presented in Figure 3.

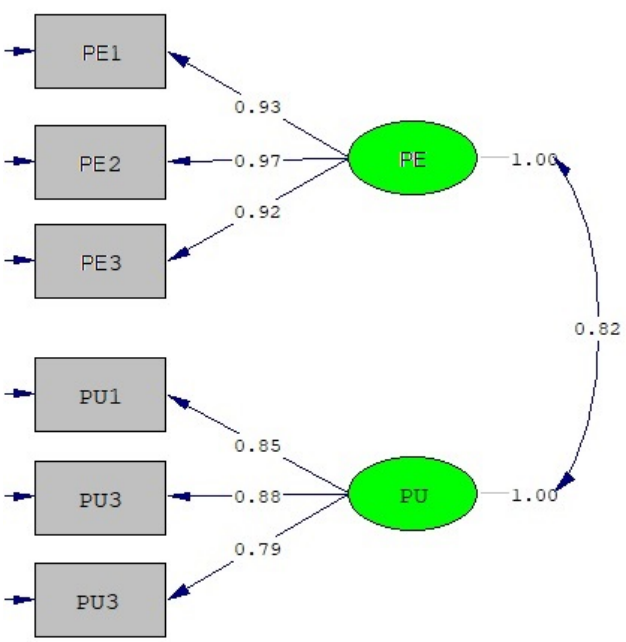

Chi-Square $=22.07, \mathrm{df}=8, \mathrm{P}-\mathrm{value}=0.00478, \mathrm{R}$ MSEA $=0.070$

Figure 3. Model estimation results $(N=354)$

The descriptive statistics (mean and standard deviation), factor loadings $(\lambda)$, and item reliability $\left(\mathrm{R}^{2}\right)$ are presented in Table 4.

Table 4. Descriptive statistics and factor loadings $(N=354)$

\begin{tabular}{|l|l|l|l|l|}
\hline Item & $\mathrm{M}$ & $\mathrm{SD}$ & $\boldsymbol{\lambda}$ & $\mathrm{R}^{2}$ \\
\hline PE1 & 3.30 & 1.38 & 0.93 & 0.86 \\
\hline PE2 & 3.22 & 1.41 & 0.97 & 0.95 \\
\hline PE3 & 3.24 & 1.46 & 0.92 & 0.86 \\
\hline PU1 & 3.51 & 1.29 & 0.85 & 0.73 \\
\hline PU2 & 3.63 & 1.29 & 0.88 & 0.77 \\
\hline PU3 & 3.83 & 1.21 & 0.79 & 0.63 \\
\hline
\end{tabular}

The correlation coefficient of 0.82 between the latent variables is statistically significant $(\mathrm{p}<.001)$.

In all cases, the loadings were over 0.8 , ranging from 0.79 to 0.97 , showing evidence for unidimensionality. The scale reliability (Cronbach's alpha) was over 0.7 for both constructs, the composite reliability (CR) above the threshold of 0.7 , and the average variance extracted (AVE) above the threshold of 0.5 , thus giving support for the convergent validity.

The model fit with the data is very good. Although the chisquare is significant, the other GOF indices are within the limits recommended by Hair et al. [H06]. The GOF indices are summarized in Table 5. 
Table 5. GOF indices $(\mathrm{N}=354)$

\begin{tabular}{|l|l|l|l|l|l|l|}
\hline$\chi^{2}$ & DF & $\chi^{2} / \mathrm{DF}$ & RMSEA & CFI & GFI & SRMR \\
\hline 22.7 & 8 & 2.84 & 0.071 & 0.99 & 0.98 & 0.017 \\
\hline
\end{tabular}

All mean values of the indicators are above the neutral value, showing that Romanian students have a high perception of intrinsic and extrinsic motivation.

\section{Invariance analysis}

Many studies that analyze group differences by applying traditional statistical significance tests are relying on the assumption that respondents are interpreting the variables in the same way. This approach may lead to ambiguous results when the variables under consideration are measures of an underlying model. In this case, an invariance analysis is needed [B10, VL00]

First, the unconstrained model on both samples taken together has been tested. The results show a non-significant chi-square $\left(\Delta \chi^{2}=26.93, \mathrm{DF}=16, \mathrm{p}=.004\right)$ and very good GOF indices $\quad(\mathrm{CFI}=0.99, \quad \mathrm{GFI}=0.98, \quad \mathrm{RMSEA}=0.052$, $\mathrm{SRMR}=0.0173$ ).

The next step is to test the metric invariance by constraining the loadings to be equivalent. Although the model comparison shows a significant chi-square difference $\left(\Delta \chi^{2}=44.84, \Delta \mathrm{DF}\right.$ $=6, p=.000)$, the depreciation of CFI is not less than 0.01 so the model exhibits metric invariance, according to the criterion of Cheung \& Rensvold [CR02]. This means that the model has been perceived in the same way in each group.

Testing the scalar invariance is done by constraining the intercepts to be equivalent. The model comparison shows a significant chi-square difference $\left(\Delta \chi^{2}=24.16, \Delta \mathrm{DF}=4, \mathrm{p}=\right.$ 0.000 ), the depreciation of CFI is less than 0.01 so the model has scalar invariance.

Table 6. Model comparison $(N=512)$

\begin{tabular}{|l|c|c|c|c|c|}
\hline Model & $\Delta \chi^{2}$ & $\Delta \mathrm{DF}$ & $\mathrm{p}$ & $\mathrm{CFI}$ & $\Delta \mathrm{CFI}$ \\
\hline Unconstraint & & & & 0.99 & \\
\hline Metric invariance & 44.84 & 6 & 0.000 & 0.98 & -0.01 \\
\hline Scalar invariance & 24.16 & 4 & 0.000 & 0.98 & 0.00 \\
\hline Error invariance & 51.41 & 6 & 0.000 & 0.96 & -0.02 \\
\hline
\end{tabular}

The test for the error variance invariance resulted in a nonsignificant chi-square difference $\left(\Delta \chi^{2}=51.41, \Delta \mathrm{DF}=6, \mathrm{p}=\right.$ 0.000 ) and a depreciation of CFI more than 0.01 which shows a lack of error variance invariance. The results of the invariance analysis are presented in Table 6 .

The metric invariance enables a comparison of the observed scores between groups.

\section{Comparison between samples}

The differences between samples are presented in Table 7 .

Table 7. Comparison between samples

\begin{tabular}{|c|c|c|c|c|c|c|}
\hline Group & PE1 & PE2 & PE3 & PU1 & PU2 & PU3 \\
\hline LT & 3.20 & 2.98 & 2.75 & 3.23 & 2.99 & 3.25 \\
\hline RO & 3.30 & 3.22 & 3.24 & 3.51 & 3.63 & 3.83 \\
\hline
\end{tabular}

In the Lithuanian sample, the mean value of PE is 2.98 which is slightly below the neutral value. The mean value of PU is 3.16 , suggesting a small positive perception of extrinsic motivation.

In the Romanian sample, the mean value of PE is 3.25 and the mean value of $\mathrm{PU}$ is 3.66 , showing a positive perception of both types of motivation.

\section{DISCUSSION}

There is no doubt that in various circumstances (in this case, due to pandemic conditions) motivation remains an essential factor. According to researchers, motivation is an indispensable reason for fostering student academic achievement $[15,37]$. Categorically, motivation would be a crucial path towards personal/social success or to academic/professional performance.

A motivated student/graduate will achieve good results, related both to a persevering effort carried out through an independent volition (at the level of desirable behaviors), but also through the successful completion of tasks focused on learning efficiency or active involvement.

However, the indicators related to academic performance and motivation are strongly associated and inter-conditioned: although the youngers' experiences are different from case to case and motivation is often explained with various personal reasons, good academic results are obtained by students with high motivation for learning.

Maybe in many cases, a decrease in motivation and learning outcomes can be associated with the pandemic, taking into account the transition from the common presential format to the online one, but also from the familiar environment (met generally in upper secondary schools) to university, especially for the students who were enrolled in the first year of study in autumn 2020. Both transitions induced a lot of pressure and there is interesting to notice if there is recorded a growth in university leaving rate, knowing that academic environment introduces an emphasis on certain learning objectives that would create a demotivating and negative psychological environment, which adversely affects the students' behaviors.

On the other hand, there is a tendency to view intrinsic and extrinsic motivation as opposites, several studies being focused exclusively on intrinsic motivation. It is important to consider and explore motivation in "real-life" online environments, taking into account a varied range of social and contextual influences [15].

The results of the presented study show that the motivation of university students for online learning is low to moderate. In both groups, intrinsic motivation is lower than extrinsic motivation. In both groups, attractiveness was the highest 


\section{Proceedings of RoCHI 2021}

scored item of the perceived enjoyment. Also, in both groups, the perceived advantage given by the online platform was the highest rated item of the perceived usefulness.

There are significant differences between groups since the motivation depends on a wide variety of conditions, such as the context of a particular country. The higher mean values in the Romanian sample could be explained in part by the perceived advantages of online lectures in engineering education that have been found in a recent study [22].

While distance learning is certainly better and perhaps even easier in terms of convenience, it is not possible to provide qualitative distance learning for certain study programs. Obviously, it is easier to teach theoretical subject material remotely, and organizing exercises or laboratory work is not so simple. Although this, of course, depends on the specifics of the subject being taught: those working in the social sciences find it easier to adapt to distance learning than those in the technical/natural sciences.

Distance learning requires both the appropriate conditions and the person's disposition and skills. The importance of motivation is extremely high. Understandably, qualitative participation in the study process is not easy, because a person's independence is determined by many different factors. A previous study conducted in Lithuania showed that the greatest motivation to participate in distance learning is personal interest and convenience [34].

The issue of motivation for distance learning was also relevant before the pandemic. There was always a need to get feedback on course design, progress, modification, and so on. Mignon and Closset [27] argued that such information is necessary to know what motivation strategy to choose, what is the risk of student demotivation, and how to avoid it. So, it is good to have several course organization designs.

The use of new technologies opens up new perspectives for every university course. It is a kind of reorganization of the courses taught. Teachers should set the goal of not compromising student motivation. One should also think about how to improve certain aspects of the practice to improve student motivation, to help the student reflect on their learning. Failure to answer these questions runs the risk of demotivating students. By knowing the risks and regularities, it is possible to avoid them. It becomes more difficult to motivate by studying remotely and in the conditions of spatial separation of students and lecturers. Geographical distance and lack of social contact generate a sense of apathy. This situation can have consequences for students' motivation and interest in the long run if we do not pay attention to it.

Thus, in the conditions of distance learning, it is necessary to create a sense of cooperation, social contacts, belonging to a group, and promoting students' self-esteem. Communication tools (email, chat rooms /social networks) can help motivate students. It is always good to combine oral language with a written one. Researchers believe that in the case of distance learning, it is better to create an impression of presence rather than reality. There is a need to respond faster to questions, to answer them, to take time to reflect on students' independent work. One of the most important things in distance learning is to manage students' independent workload.

Another question is how much the student himself is interested in developing his competencies, whether the tasks offered by the lecturer give the student enthusiasm to learn. In distance learning, lecturers need to instruct more often, explain what is expected of the student, explain how to make better use of the online environment. The activities offered by lecturers in the eyes of students must be meaningful, different, adaptable, and in the learning of other subjects. Students must also be left with challenges. The result of the activity should not be very easy to achieve, but to influence the competencies developed by the student. Thus, original, non-repetitive activities, application of different learning strategies, various methods - a guarantee of maintaining motivation. Although, of course, for some students, the variety of activities and the abundance of methods can be stressful. In the context of cognitive psychology, academic motivation is defined as student engagement, participation, and perseverance in performing tasks.

There are several limitations of this exploratory study. First, the Lithuanian sample is small and gender unbalanced. Second, the pandemic radically changed teaching and learning and this affected both students and teachers. In many cases, the answer to the crisis was inadequate.

\section{CONCLUSION AND FUTURE WORK}

This study contributes to a better understanding of two factors driving the acceptance of online teaching and learning in the context created by the pandemic: perceived enjoyment and perceived usefulness. The first factor - perceived enjoyment is understood as intrinsic motivation while the second factor - perceived usefulness - is understood as extrinsic motivation.

Basically, most research studies only state that learning motivation is one of the most important components of learning success and related constructs. Conditions that may weaken or enhance learning motivation are also analyzed. Near intrinsic motivation, the extrinsic one plays an important role, even this motivation comes from external factors. But the biggest problem remains the students who do not want to study (or their motivation to study is low).

What is the difference between the motivation of those who want to and those who do not want to learn? How can lecturers help change the motivation of unmotivated students for learning? It is obvious that the activation/engagement of students in the study process remains universal, never loses its relevance and therefore the problem must be addressed in the future.

\section{REFERENCES}

1. Amrai, K., Motlagh, S.E.,Zalani, H.A., \& Parhon, H. (2011). The relationship between academic motivation and academic achievement students. Procedia - Social 


\section{Proceedings of RoCHI 2021}

and Behavioral Sciences, 15, 399-402. DOI 10.1016/j.sbspro.2011.03.111

2. Byrne, B. (2010). Structural Equation Modeling with AMOS. Basic Concepts, Applications, and Programming. Lawrence Erlbaum Association.

3. Cascio, W., \& Montealegre, R. (2016). How Technology Is Changing Work and Organizations. Annual Review of Organizational Psychology and Organizational Behavior, 3(1), 349-375, DOI: 10.1146/annurev-orgpsych-041015-062352

4. Cheung, G.W., \& Rensvold, R.B. (2002). Evaluating goodness-of-fit indexes for testing measurement invariance. Structural Equation Modelling 9(2), 233255.

5. Coman, C., Țîru, L.G., Meseșan-Schmitz, L., Stanciu, C., \& Bularcă, M.C. (2020). Online Teaching and Learning in Higher Education during the Coronavirus Pandemic: Students' Perspective. Sustainability, 12(24), MDPI, 1-24, DOI: 10.3390/su122410367

6. Daniels, L.M., Goegan, L.D., \& Parker, P.C. (2021). The impact of COVID-19 triggered changes to instruction and assessment on university students' self-reported motivation, engagement, and perceptions. Social Psychology of Education, 24, 299-318. DOI:10.1007/s11218-021-09612-3

7. Davis, F.D. (1989). Perceived Usefulness, Perceived Ease of Use, and User Acceptance of Information Technology. MIS Quarterly, 13(3), 319-340.

8. Davis, F.D., Bagozzi, R.P., \& Warshaw, P.R. (1992). Extrinsic and intrinsic motivation to use computers in the workplace. Journal of Applied Social Psychology, 22(14), 1111-1132.

9. Deci, E.L., Vallerand, R.J., Pelletier, L.G., \& Ryan, R.M. (1991). Motivation and education: The selfdetermination perspective. Educational psychologist, 26(3-4), 325-346.

10. Deci, E.L., \& Ryan, R.M. (2008). Self-determination theory: A macro theory of human motivation, development, and health. Canadian Psychology, 49(3), 182-185.

11. Dhawan, S. (2020). Online learning: A panacea in the time of the COVID-19 crisis. Journal of Educational Technology Systems, 49(1), 5-22. https://doi.org/10.1177/0047239520934018

12. Fornell, C., \& Larcker, D.F. (1981). Evaluating structural equation models with unobservable variables and measurement error. Journal of Marketing Research, 18(1), 39-50.

13. Hair, J.F., Black, W.C., Babin, B.J., \& Anderson, R. (2006). Multivariate Data Analysis. 6th Ed., PrenticeHall.

14. Hassenzahl, M. (2005). The Thing and I: Understanding the Relationship Between User and Product. In Blythe, M., Overbeeke, K., Monk, A., and Wright, P. (Eds.). Funology: From Usability to Enjoyment. Kluwer Academic Publishers, 31-42.

15. Hartnett, M. (2016). The importance of motivation in online learning. In: M. Hartnett (Ed.), Motivation in online education, 5-32. Springer. https://doi.org/10.1007/978-981-10-0700-2 2

16. Heijden, H. van der (2004). User acceptance of hedonic information systems. MIS Quarterly 28(4), 695-704.

17. Hornbæk, K., \& Hertzum, M. (2017). Technology Acceptance and User Experience: A Review of the Experiential Component in HCI. ACMTrans. Comput.Hum. Interact. 24(5), Article 33 (October 2017), 30 pages, DOI: 10.1145/3127358.

18. Kulikowski, K., Przytuła, S., \& Sułkowski, Ł. (2021). The Motivation of Academics in Remote Teaching during the Covid-19 Pandemic in Polish Universities Opening the Debate on a New Equilibrium in eLearning. Sustainability, 13, 1-16. DOI:10.3390/su13052752

19. Lamanauskas, V., Slekiene, V., Gorghiu, G., \& Pribeanu, C. (2019). Better learning and increased motivation to learn with mobile technology (devices): A preliminary study. Natural Science Education 16(2), 8088. DOI: $10.48127 /$ gu-nse/19.16.80

20. Lee, M.K.O., Cheung, C.M.K., \& Chen, Z. (2005). Acceptance of Internet-based learning medium: the role of extrinsic and intrinsic motivation. Information and Management, 42(3), 1095-1104.

21. Malinauskas R.K., \& Pozeriene, J. (2020). Academic Motivation Among Traditional and Online University Students. European Journal of Contemporary Education, 9(3), 584-591 DOI: 10.13187/ejced.2020.3.584

22. Manea, I.V., Macavei, T., \& Pribeanu, C. (2021). Perceived benefits of online lectures during the pandemic: a case study in engineering education. Pro Edu International Journal of Educational Sciences, 3(1), 35-41, DOI: 10.26520/peijes.2021.4.5.65-41.

23. Mardesci, H. (2020). The Effect of Online Learning on University Students' Learning Motivation. Jurnal pendidikan dan pembelajaran, 27(1), 42-47. https://www.researchgate.net/publication/34648297 4_The_Effect_of_Online_Learning_on_University_ Students'_Learning_Motivation

24. Maqbool, S., Ismail, S., A.M.M., \& Maqbool, S. (2020). A correlational study between learning motivation and satisfaction in online courses. Humanities \& Social Sciences Reviews, 8(1), 716-724. DOI: 10.18510/hssr.2020.8186

25. Manuel, A. A. M., Buque, D., \& Quive, R. (2021). Students' perceptions on distance education: A case study in Mozambique. Problems of Education in the $21^{\text {st }}$ Century, 79(2), 229-240. https://doi.org/10.33225/pec/21.79.229

26. Mels, G. (2006). LISREL for Windows: Getting started guide. Scientific Software International.

27. Mignon, J., \& Closset, J.-L. (2004). Maintien et stratégies de renforcement de la motivation des étudiants dans l'enseignement à distance [Maintenance and strategies to strengthen student motivation in distance education]. In L'AIPU: 20 ans de Recherches 


\section{Proceedings of RoCHI 2021}

et d'Actions Pédagogiques; Bilan et Perspectives" 21ème Congrès de l'AIPU 3-7 Mai 2004, Université Cadi Ayyad, Marrakech, Maroc.

https://www.researchgate.net/publication/228084123

28. Milfont T.L., \& Fischer R. (2010). Testing measurement invariance across groups. Applications in cross-cultural research. International Journal of Psychological Research, 3(1), 112-131.

29. Mishra, L., Gupta, T., \& Shree, A. (2020) Online teaching-learning in higher education during lockdown period of COVID-19 pandemic, International Journal of Educational Research Open, 1, https://doi.org/10.1016/j.ijedro.2020.100012

30. Mun, Y.Y., \& Hwang, Y. (2003). Predicting the use of web-based information systems: self-efficacy, enjoyment, learning goal orientation, and the technology acceptance model. International Journal of Human-computer Studies, 59(4), 431-449.

31. Pal, D., \& Vanijja, V. (2020). Perceived usability evaluation of Microsoft Teams as an online learning platform during COVID-19 using system usability scale and technology acceptance model in India. Children and youth services review, 119, 105535.

32. Qureshi, E., Morton, L.L., \& Antosz, E. (2002). An interesting profile-university students who take distance education courses show weaker motivation than oncampus students. Online Journal of Distance Learning Administration, 5(4).

https://www.westga.edu/ distance/ojdla/winter54/Quers hi54.htm
33. Rahiem, M.D.H. (2021). Remaining motivated despite the limitations: university students' learning propensity during the covid-19 pandemic. Children and Youth Services Review, 120, 1-14. DOI:10.1016/j.childyouth.2020.105802

34. Rutkienè, A., \& Trepule, E. (2009). Nuotolinis suaugusiujjų mokymas(is) mokymosi visą gyvenimą kontekste [adult distance education and learning in lifelong learning]. Acta Paedagogica Vilnensia, 23, 2942.

35. Schermelleh-Engel, K., Moosbrugger, H., \& Müller, H. (2003). Evaluating the fit of structural equation models: Tests of significance and descriptive goodness-of-fit measures. Methods of psychological research online, $8(2), 23-74$

36. Sharma, K., Giannakos, M., \& Dillenbourg, P. (2020). Eye-tracking and artificial intelligence to enhance motivation and learning. Smart Learning Environments. 7(13), 1-19. DOI:10.1186/s40561-020-00122-x.

37. Serin, H. (2018). The use of extrinsic and intrinsic motivations to enhance student achievement in educational settings. International Journal of Social Sciences \& Educational Studies, 5(1), 191-194. https://doi.org/10.23918/ijsses.v5ilp191

38. Vandenberg, R.J., \& Lance, C.E. (2000). A review and synthesis of the measurement invariance literature: suggestions, practices, and recommendations for organizational research. Organizational Research Methods 3(1), 4-70. 